\title{
PATHOLOGICAL LESIONS IN DIFFERENT ORGANS AFTER CHRONIC XYLENE AND UVB EXPOSURE IN MICE
}

\author{
AHMAD H. MEHDI ${ }^{1}$; SNUR MA HASSAN ${ }^{2}$; AZAD K SAEED ${ }^{2}$ and IMAN Y. MOHAMMED ${ }^{3}$ \\ ${ }^{1}$ Department of Pathology and Forensic Pathology, School of Medicine, Faculty of Medical Sciences, Sulaimani University, \\ Kurdistan Region - Iraq \\ ${ }^{2}$ Department of Anatomy and Histopathology, College of Veterinary Medicine, Sulaimani University, Kurdistan Region - \\ Iraq \\ ${ }^{3}$ Department of Pathology and Forensic Pathology, School of Medicine, Faculty of Medical Sciences, Sulaimani University, \\ Kurdistan Region - Iraq
}

Received: 17 April 2016; Accepted: 7 June 2016

\begin{abstract}
The present study was designed to investigate the pathological lesions in different organs induced by chronic Ultraviolet type B (UVB) and Xylene exposure in mice. Forty mice were used in this study and divided into four groups; Group A (Control group, $n=10)$ not exposed to UVB and Xylene, Group B $(n=10)$ exposed to Xylene through painting the mouse's back skin, Group $\mathrm{C}(\mathrm{n}=10)$ which were exposed to UVB light only, while the remainder group (Group D, $n=10$ ) were exposed to Xylene and UVB. The dorsal skin of mice from group B and D were painted with $1 \mathrm{ml}$ of Xylene whereas the animals in the group C and D exposed to UVB light for 30 minutes 4 days/week ( 6 weeks). The result showed that Xylene exposure in group B produced chronic tracheitis, bronchitis with some degenerative lesions in the neurons and glial cells of the brain, no specific lesions were found in the liver, spleen and kidney. UVB exposure in group C caused chronic tracheitis, lesions like lobar pneumonia, bronchopneumonia, and atelectasis, cellular swelling in the liver and kidney and follicular depletion in the spleen. In group D, the lesions became more prominent when animals exposed to both Xylene and UVB. We concluded that Xylene exposure has an adverse effect in some internal organs of mice, but not to all, when combined with UVB exposure it exaggerates its adverse effects on all of the examined organs.
\end{abstract}

Key words: Histopathologic lesions, UVB, and Xylene.

\section{INTRODUCTION}

In the past, the wrinkle, mottling, excrescences, and flaccidity of aging skin were considered as inevitable "natural" characters of aging. Recently, it is clearly illuminated that the only passage of time is not enough to produce these changes. The ravages associated with aging are mainly a result of excessive sun exposure (Kligman et al., 1982, Tsukahara et al., 2005, Saeed and Salmo 2012, Hassan et al., 2015). For the majority of people, the sun is the most important source of exposure; body sites will receive different amounts of UV depending on their orientation with respect to the sun and on reflection from ground surfaces (Belkin et al., 1995). Ozone depletion and changes in lifestyles are likely reason to increase exposure to sunlight,

Corresponding author: Dr. AZAD K SAEED

E-mail address: azad.saeed@univsul.edu.iq

Present address: Department of Anatomy and Histopathology, College of Veterinary Medicine, Sulaimani University, Kurdistan Region - Iraq, including the UVB waveband. Such irradiation may induce immunomodulation and, therefore, have adverse effects on human health (Garssen et al., 1999). Many acute and chronic health damages to the skin, eyes, and immune system of humans are caused by prolonged exposure to solar UV radiation (Gurish et al., 1981, Ouhtit et al., 2000, Ullrich et al., 2002, Chang and Zheng 2003, Chen 2013). Acute UVB irradiation in human skin produces erythema, edema, and skin pigmentation, thickening of the epidermis and dermis, and synthesis of vitamin D. While chronic UVB effects are photo aging, immunosuppression, and photocarcinogenesis (Anitha, 2012).

It is well known that in the workplace, employees are exposed simultaneously or sequentially to several chemicals. The degree of chemical exposure and, hence the toxicological risk can be assessed by either environmental or biological monitoring (Tardif et al., 1991). Xylene as a solvent and cleaning agent is used most commonly in histopathological laboratories, printing, painting, rubber and leather industries 
(Savolainen et al., 1978, Savolainen et al., 1979, Savolainen et al., 1981, Savolainen et al., 1984, Mohtashamipur et al., 1985, Richer et al., 1993, Kandyala et al., 2010). Occupational exposure to xylene may result from the use of the compound in paints, varnishes, glues and printing inks, and in the rubber and leather industries. Skin contact with the solvent may occur in actual work situations, but normally inhalation is the main route of xylene absorption (Laine et al., 1993 and Richer et al., 1993). Our previous study showed that chronic skin exposure to xylene induced epidermal hyperplasia when combined with UVB its effect were accelerated (Hassan et al., 2015). To further elucidate behavioral xylene toxicology, the current study was designed to demonstrate the pathological lesions in different organs induced by chronic UVB and Xylene exposure in $\mathrm{BALB} / \mathrm{c}$ mice.

\section{MATERIALS AND METHODS}

\section{A- Animal model}

Forty adult albino mice from Mus musculus species, $B A L B / c$ strain (20 males and 20 females) was used in this experiment, which had free access to water and food. Animals were housed in the animal house Department of Biology/School of Science/Sulaimani University, the room temperature was $25^{\circ} \mathrm{C}$ and where the lighting was automatically controlled on 12 hours light/dark cycle. Mice were divided into four groups; Group A (Control group, $n=10$ ) which were not exposed to UVB and Xylene spraying, Group B $(n=10)$ exposed to Xylene only, Group C $(n=10)$ which were exposed to UVB light only, while the remainder group (Group D, $n=10$ ) were exposed to Xylene and UVB.

\section{B-Xylene exposure}

Electrical clippers were used to make a window $(2 * 5$ $\mathrm{cm}$ ) on the mouse's back skin, then each mouse from group B and D was painted $1 \mathrm{ml}$ of Xylene (Surechem product LTD, Needham market Suffolk England) (Hassan et al., 2015). This process was performed 4days/week for 6 consecutive weeks.

\section{$C$ - UVB irradiation}

The source of UVB irradiation in this project was a Lamp with $312 \mathrm{~nm}$ wavelength, 15 Watts, Vilber-
Lourmat-France, with a calculated power $80 \mathrm{mj} / \mathrm{Sec}$. Mice from group C and D were exposed to UVB light for 30 minutes 4 days/week (6 weeks) consecutively.

\section{D- Sample collections}

At the end of the project, the mice were euthanized by using Xylazine-Ketamine intraperitoneally as the recommended dose. Tissue samples were taken from different organs, including trachea, lung, liver, spleen and kidney. The specimens were fixed at $10 \%$ neutral buffered formalin for 24 hours and then routinely processed in the Pathology Lab/International hospital/Sulaimani Governorate. Samples were embedded paraffin and cut at a $5 \mu \mathrm{m}$ section, then stained with conventional Hematoxylin and Eosin and examined by light microscopy.

\section{RESULTS}

Tissue sections from different organs were examined under the light microscope and the lesions that observed were listed as follows:

Trachea: In the control group (group A) microscopical examination showed a normal histologic view of the trachea (Mucosa, submucosa, adventitia), the mucosa is lined by pseudostratified ciliated columnar epithelium interspersed with goblet cells. The lamina propria contains fine connective tissue fibers, diffuse lymphatic tissue (Fig. 1a). In group B, microscopical sections showed focal mild infiltration of mononuclear cells and edema in the lamina propria (Fig. 1b). In group C, variable lesions were observed, including moderate subepithelial infiltration of mononuclear inflammatory cells predominately lymphocytes, plasma cells with few macrophages and edema in the lamina propria (Fig. 1c) with focal degeneration of tracheal glands (Fig. 1d). Whereas lesions in the group D were more severe in comparison to the above groups, the lumen contained necrotic debris, the epithelium demonstrated multifocal sloughing (Fig. 1e), while the surviving epithelium revealed focal squamous metaplasia (Fig. 1f). Diffuse infiltration of mononuclear inflammatory cells and edema with a complete degeneration of tracheal glands and hyaline cartilages were also seen (Fig. 1g-h). 

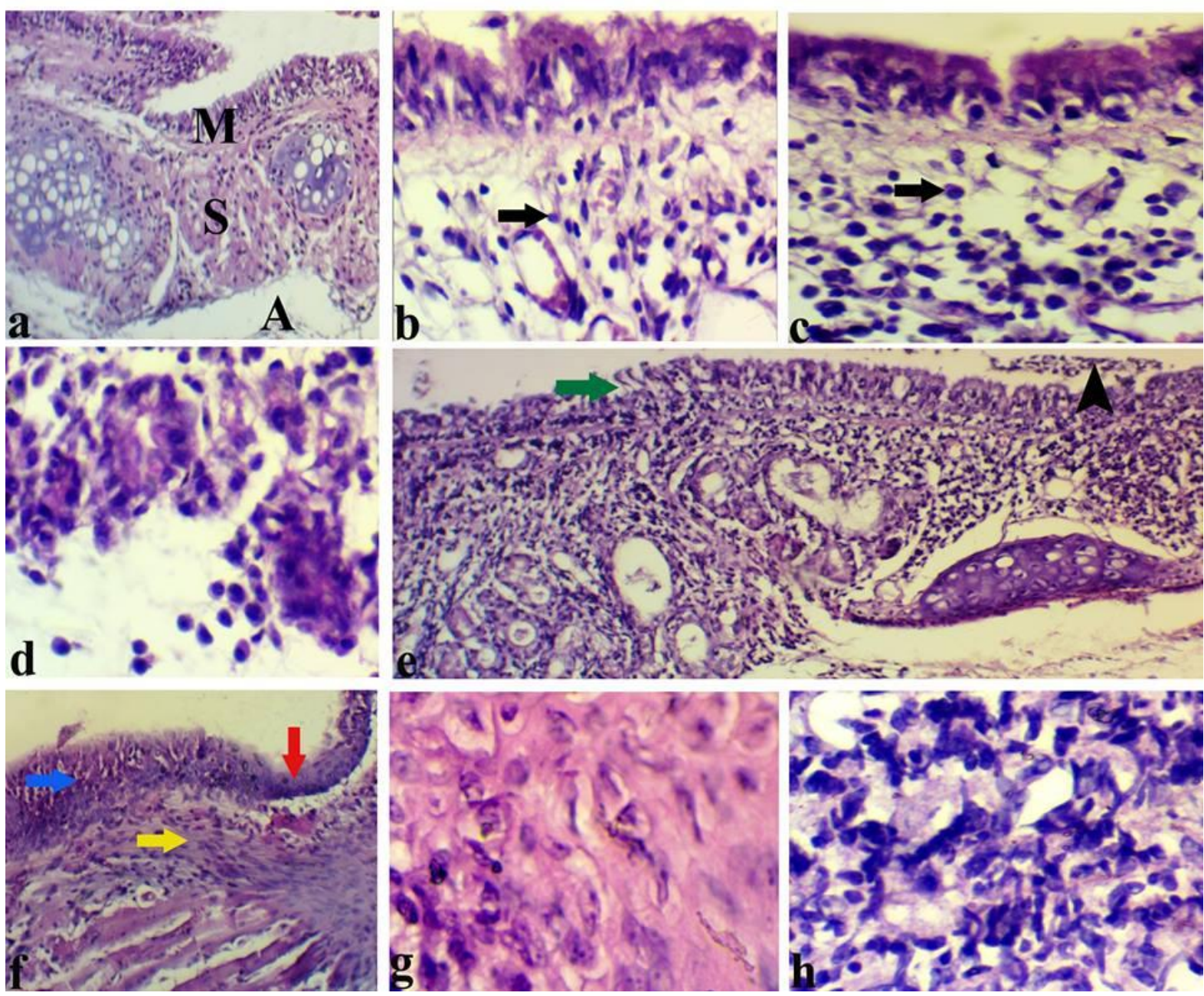

Fig. 1: (a) Histologic view of normal trachea composed of 3 distinct layers: mucosa (M), submucosa (S) and adventitia (A) (H\&E stain, 40x), (b) Mild infiltration of mononuclear inflammatory cells as indicated by black arrow with edema in the lamina propria in group B (H\&E stains, 400x), (c) Moderate infiltration of mononuclear inflammatory cells (black arrow) with edema (H\&E stains, 400x), (d) Focal degeneration of tracheal glands (H\&E stains, 400x), (e-h) Histologic view of the trachea in group D shows sloughing of epithelial cells (green arrow), necrosis (black arrow head and blue arrow), metaplastic change (red arrow), diffuse infiltration of mononuclear inflammatory cells with complete degeneration of tracheal gland and fibrosis as indicated by yellow arrow (H\&E stains, 100x and 400x).

Lung: Lung specimens in the group A, revealed healthy intra pulmonary airways (Fig. 2a), whereas in group B, most of the lesions were restricted the conducting portions principally to terminal bronchiole without involving the respiratory portions, i.e. it produced bronchiolitis as indicated by the presence of necrotic debris with large numbers of RBCs in the lumen of bronchioles, with infiltrations of mononuclear inflammatory cells in the peribronchiolar space with no signs of leukocytic alveolitis (Fig. 2b). Samples in the Group C, showed necrotic debris in most of the conducting portion from bronchi to respiratory bronchioles, the whole blood vessels were engorged with blood, infiltration of mononuclear cells in alveolar spaces and peribronchiolar spaces (Leukocytic alveolitis and bronchiolitis "Bronchopneumonia"), associated with partial atelectasis marked by thickening of the alveolar walls (Fig. 2c-f); the last group (group D) showed congestion in the pulmonary blood vessels, destruction of the bronchioles and alveoli, extensive peribronchiolar fibrosis with the presence of mononuclear inflammatory cells in the alveolar spaces and alveolar septa (Interstitial pneumonia) as shown in Fig. 2g-i. 

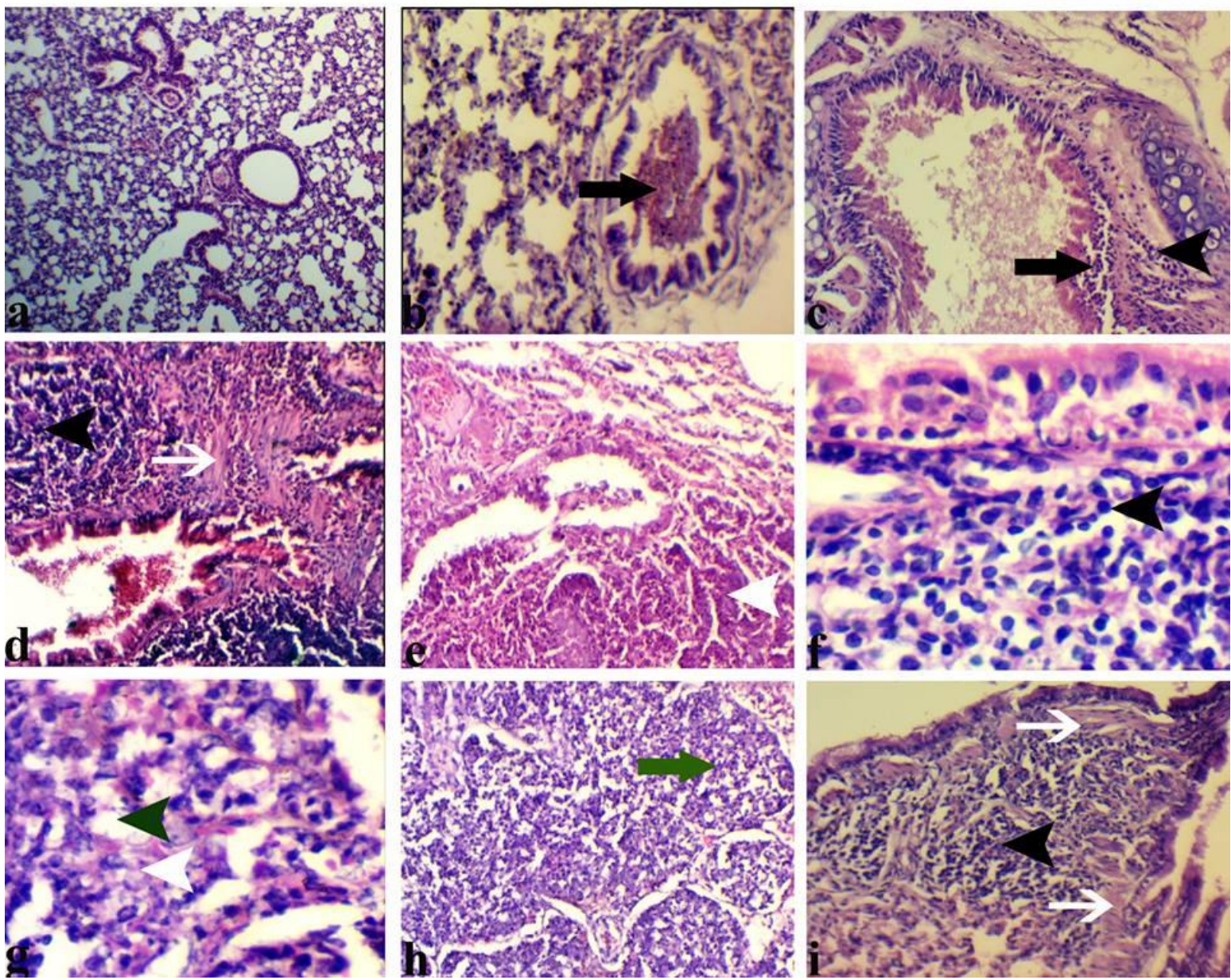

Fig. 2: (a) Normal mouse histology of the lung (H\&E stains, 40x), (b) Presence of necrotic debris with large numbers of RBCs in the lumen of bronchioles "Black arrow", with infiltrations of mononuclear inflammatory cells in the peribronchiolar space (H\&E stains, 100x), (c-f) Different lesions in group C samples which are showing RBCs and necrotic debris in the lumen of pulmonary bronchi "Black arrows in d-e" (c), (d) Peribronchiolar infiltration of mononuclear cells "Black arrow head" and fibrosis "White arrow" (H\&E stains, 100x), (e) Thickening of the alveolar walls that lead to reduction in the alveolar spaces "White arrow head", (f) Diffuse infiltration of mononuclear cells in the subepithelial space "Black arrow head" (H\&E stains, 400x), (g) Interstitial pneumonia marked by thickening of alveolar walls "White arrow head" with reduction of alveolar spaces "Green arrow head" (H\&E stains, 400x), (h) The alveoli filled by inflammatory cells "Green arrow" "Leukocytic alveolitis" (H\&E stains, 100x), and (i) Diffuse chronic inflammatory cells "Black arrow head" with fibrosis "White arrows" (H\&E stains, 100x).

Liver: Livers of the control group had the normal architecture (Fig. 3a). In group B, no remarkable microscopic changes were observed other than mild vascular congestion. In group $\mathrm{C}$, there was congestion in central veins, and sinusoids. The hepatocytes, especially in the centrilobular zone, showed vacuolar degeneration (Fig. 3b) with infiltration of mononuclear cells, and in some regions, there was dilatation of sinusoids with atrophy of adjacent hepatocytes (Fig. 3c). More extensive lesions were observed in the group D, including pericentral necrosis, infiltration of mononuclear cells, dilation of sinusoids with atrophy of surviving hepatocytes (Fig. 3de). 

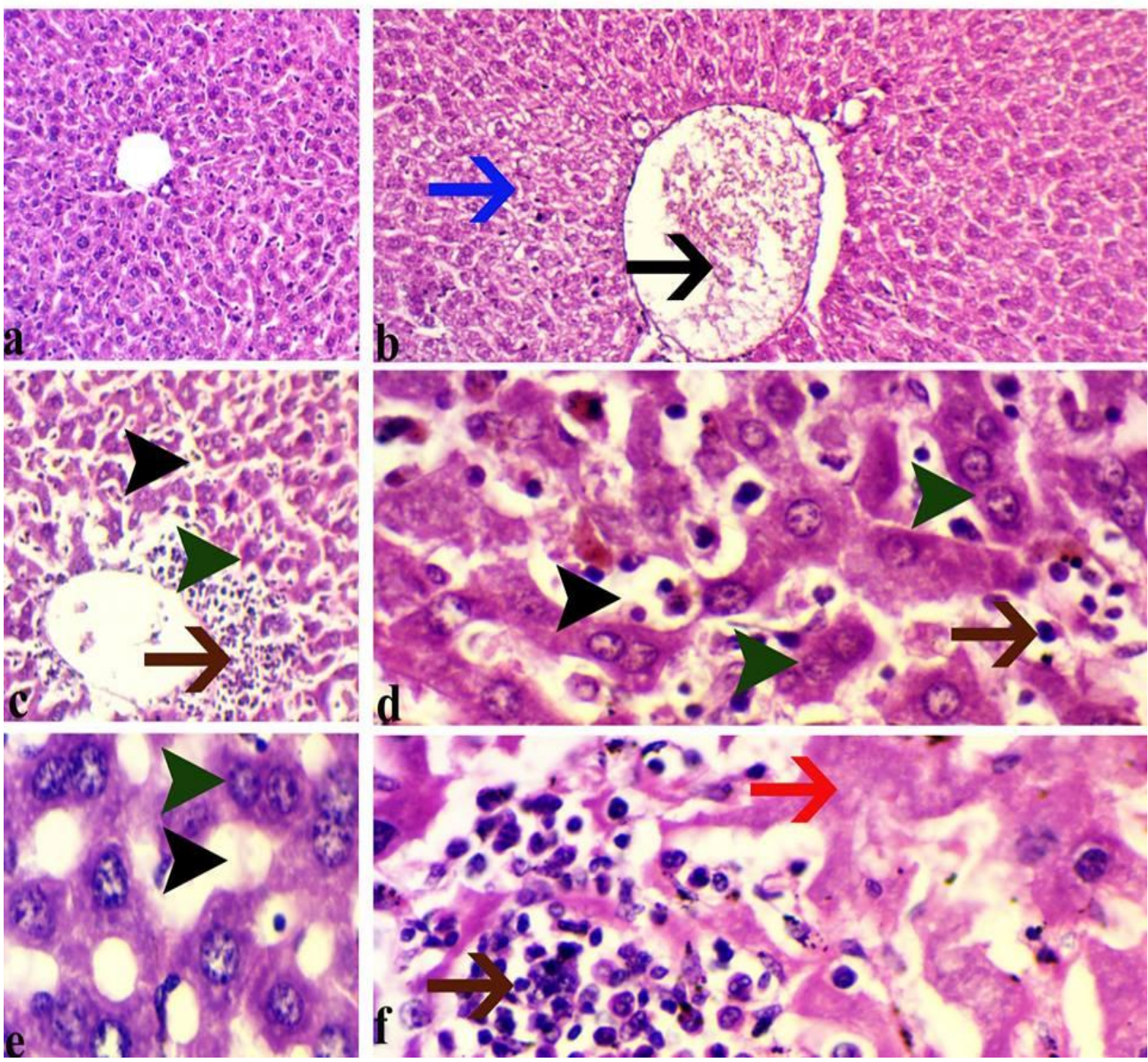

Fig. 3: (a) Normal histology of mouse's liver, (b) Aggregation of RBCs in the central vein "Black arrow" with swelling of hepatocytes "Blue arrow" (H\&E stains, 100x), (c-e) Pericentrilobular and sinusoidal infiltration of mononuclear cells "Brown arrows" with dilatation of sinusoids "Black arrow heads" and atrophy of hepatocytes "Green arrow heads" (H\&E stains, 100x, 400x), and (f) most of the hepatocytes show necrotic changes "Red arrow" with adjacent inflammatory cells (H\&E stains, 400x).

Spleen: Microscopic examinations in group A, showed the normal histological appearance of both white and red pulps (Fig. 4a). Spleen specimens from group B, remained normal without any pathological observations. In group $\mathrm{C}$, depletion of lymphoid follicles, severe infiltration of mononuclear cells, and focal deposition of eosinophilic, proteinaceous material (Fibrinous exudation) in the white pulps (Fig. 4b-c). In group D, the lesions were present in advance state such as exudation of fibrinous materials in white and red pulps with follicular depletions and mononuclear inflammatory cells in the red pulps (Fig. 4d). 

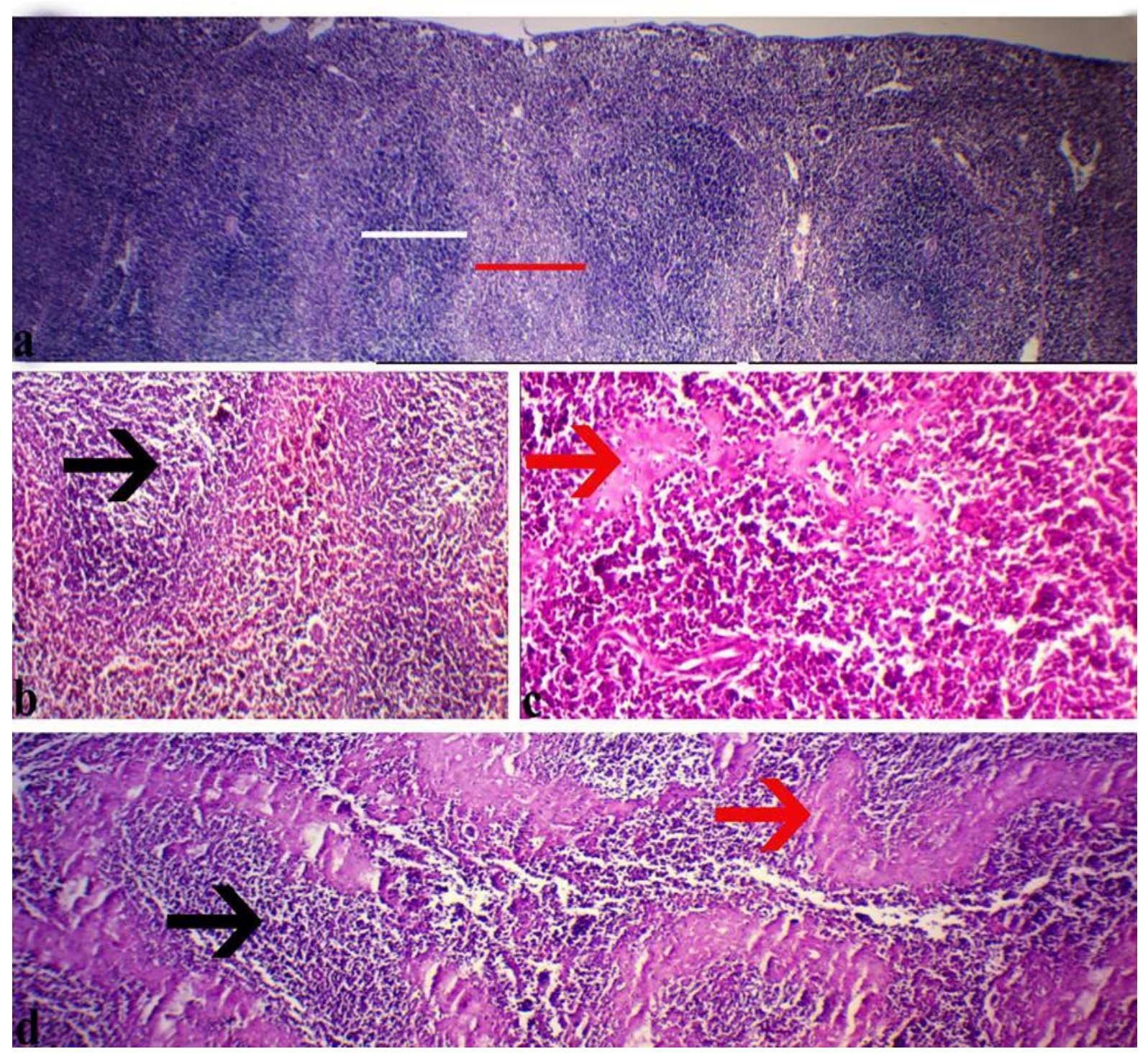

Fig. 4: (a) Normal histologic appearance of mouse's spleen composed of two different zones: White pulps "White line" and red pulps "Red line" (H\&E stains, 40x), (b) Depletion of lymphoid follicles "Black arrow" (H\&E stains, 100x), (c) Focal deposition of fibrinous eosinophilic, proteinaceous materials in the white pulp "Red arrow" (H\&E stains, 100x) and (d) Diffuse fibrinous exudation "Red arrow" with follicular depletion "Black arrow" (H\&E stains, 200x).

Kidney: Mice from the control group (group A), showed the normal components of the kidney (Fig. 5a-b). No pathological lesions were found in group $\mathrm{B}$, while, in group $\mathrm{C}$, mild degeneration of epithelial cells in the convoluted tubules with narrowing of the lumen, atrophy of glomeruli (Fig. 5c), and vascular renal congestion with a presence of mononuclear inflammatory cells in the interstitial tissue. In group D, there was moderate to severe epithelial degeneration of renal tubules, mononuclear inflammatory cells, congestion of blood vessels with interstitial hemorrhage, and atrophying of the renal corpuscles with decreasing cellularity (Fig. 5d-f). 


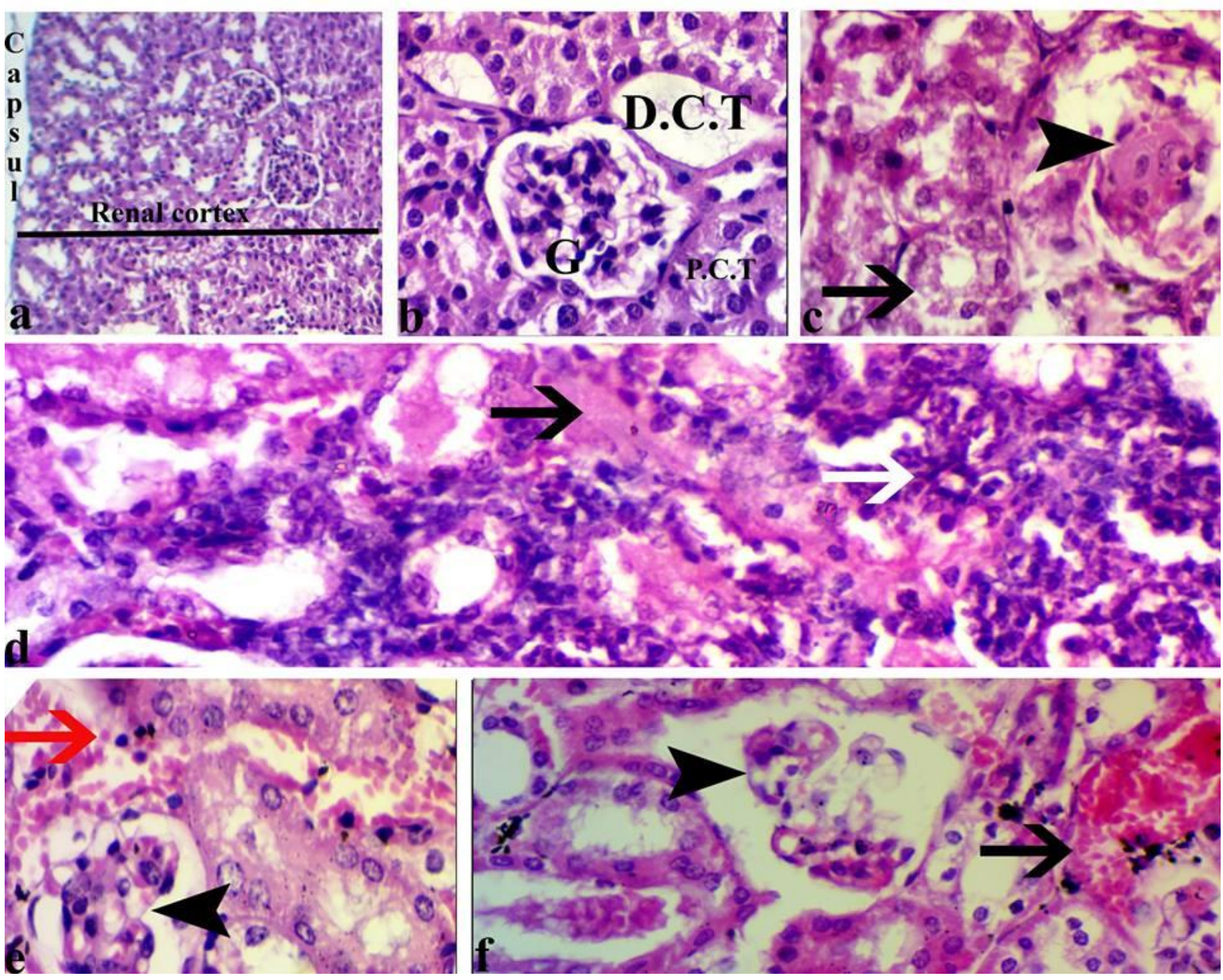

Fig. 5: (a-b) shows normal mouse kidney, distal convoluted tubule (D.C.T), proximal convoluted tubule (P.C.T) and glomerulus $(\mathrm{G})(\mathrm{H} \& \mathrm{E}$ stains, 40x, 100x), vacuolar degeneration of renal tubular epithelium "Black arrow" with glomerulus atrophy "Arrow head" (H\&E stains, 400x), (d) Necrosis in the renal tubular epithelium "Black arrow" with mononuclear inflammatory cells "White arrow" (H\&E stains, 400x), (e-f) show RBCs in the interstitial spaces "Red arrow" with decreasing cellularity of glomeruli "Arrow heads" and vascular congestion "Black arrow" (H\&E stains, 400x).

\section{DISCUSSION}

Skin is the most susceptible organ to damage by UV light as it is directly exposed. It causes a number of biological effects, many of which are detrimental. The mechanisms of UV damage on the skin have been well documented through induction of inflammatory responses, generation of free radicals and immunosuppression (Hruza and Pentland, 1993, Clydesdale et al., 2001). The current study showed the inflammatory effect of UVB on most of the internal organs up to our knowledge, no previous studies have mentioned the histopathologic role of UV radiation on internal organs most of them emphasized on cutaneous lesions induced by UV, therefore, the mechanisms by which mediators induce this clinical response remain poorly defined (Hruza and Pentland, 1993). There has been a previous study reported that UV inhibits immunity in internal organs, including activation of CD8 $\mathrm{T}$ cells and cytotoxic T cell activity in the spleen, and memory $\mathrm{T}$ cell activation in the spleen and bone marrow (Halliday et al., 2012).

Inhalation exposure to high xylene concentrations have been associated with nose and throat irritation, labored breathing, and impaired lung function in humans. Similar symptoms have been observed in animal studies (Drive, 2004). In our study, we observed that xylene painting induced a lot of changes in respiratory system, particularly in the trachea and lung, which were ranged from sloughing epithelium, induction of inflammatory responses to metaplastic change in trachea.

There is some evidence from animal studies that rats exposed to xylene vapor for one year had increased liver weights and some other very minor effects considered as an adaptive response. Rats exposed orally to 500 milligrams per kilogram of bodyweight 
(mg/kg/day) for approximately two years had increased liver and kidney weights, considered to be adaptive responses, but no adverse changes to these organs were noted upon examination (Drive, 2004). Our results demonstrated that no pathological lesions were found in the liver and kidney of group B, whereas in group D cellular swelling were observed in both liver and kidney specimens. This finding is somewhat compatible with a previous study which reported the predominant effects of repeat exposures to xylenes administered by inhalation or orally were mild hepatic alterations that were considered adaptive responses to hydrocarbon exposure (Protection, 2000).

Xylenes do not appear to affect the immune system in animals and limited human data does not demonstrate diminished immunological reactivity. Repeated oral exposure to meta-, para-, or ortho-isomers for 10 days at oral doses up to $2000 \mathrm{mg} / \mathrm{kg} /$ day increased liver weight, but slight decreases in thymus or spleen weight were only seen with p-xylene exposure. Mixed xylenes did not induce any organ weight changes (Protection, 2000). In our experiment xylene painting alone didn't produce any lesions in the spleen of group B, while in group D in combination with UVB exposure produced fibrinous exudation and follicular depletion.

\section{CONCLUSION}

Our results revealed that trachea and lung are more susceptible to xylene exposure while the other organ like liver, kidney and spleen remain resistant. Unlike xylene exposure, UVB exposure produced inflammatory changes in all of the organs; these changes are provoked when UVB exposure combined with xylene exposure. Further studies will be needed to explore the whole mechanisms that played a role in the induction of those pathologic lesions.

\section{REFERENCES}

Anitha, T. (2012): Medicinal plants used in skin protection. Asian Journal of Pharmaceutical and Clinical Research, 5(3), 35-38.

Belkin, M.; Césarini, J.; Diffey, B.; Hietanen, M.; Kojima, M.; Mariutti, G.; McKinlay, A.; Repacholi, M.; Roy, C. and Rubenstein, R. (1995): Protection Against Exposure to Ultraviolet Radiation. World Health Organisation, Genf.

Chang, C. and Zheng, R. (2003): Effects of ultraviolet $\mathrm{B}$ on epidermal morphology, shedding, lipid peroxide, and antioxidant enzymes in Cope's rat snake. Journal of Photochemistry and Photobiology B: Biology, 72(1), 79-85.
Chen, Y.-C. (2013): UV and aerosol climatology based on simulations and measurements by satellites and ground station. Dissertation for the degree of Philosophiae Doctor (PhD). Department of Physics and Technology. University of Bergen.

Clydesdale, G.J.; Dandie, G.W. and Muller, H.K. (2001): Ultraviolet light induced injury: immunological and inflammatory effects. Immunology and Cell Biology, 79(6), 547-568.

Drive, H. (2004): Mixed Xylenes (meta-, ortho-, para-): Health Information Summary. Environmental fact sheet, 603(271-3503), 1-2.

Garssen, J.; Norval, M. and Van Loveren, H. (1999): UV-B induced immunomodulation: a health risk. Polar Research, 18(2), 339-343.

Gurish, M.F.; Roberts, L.K.; Krueger, G.G. and Daynes, R.A. (1981): The effect of various sunscreen agents on skin damage and the induction of tumor susceptibility in mice subjected to ultraviolet irradiation. Journal of investigative dermatology, 76(4), 246-251.

Halliday, G.M.; Damian, D.L.; Rana, S. and Byrne, S.N. (2012): The suppressive effects of ultraviolet radiation on immunity in the skin and internal organs: implications for autoimmunity. Journal of dermatological science, 66(3), 176-182.

Hassan, S.M.; Saeed, A.K. and Mehdi, A.H. (2015): Histopathologic effect of Xylene and Ultraviolet Type B exposure on mouse skin. Int. J. Curr. Microbiol. App. Sci, 4(5), 9971004.

Hassan, S.M.A.; Hussein, A.J. and Saeed, A.K. (2015): Role of Green Tea in Reducing Epidermal Thickness upon Ultraviolet Light-B Injury in BALB/c Mice. Advances in Biology, 2015.

Hruza, L.L. and Pentland, A.P. (1993): Mechanisms of UV-induced inflammation. The Journal of investigative dermatology, 100(1), 35S-41S.

Kandyala, R.; Raghavendra, S.P.C. and Rajasekharan, S.T. (2010): Xylene: An overview of its health hazards and preventive measures. Journal of oral and maxillofacial pathology: JOMFP, 14(1), 1.

Kligman, L.H.; Akin, F.J. and Kligman, A.M. (1982): Prevention of ultraviolet damage to the dermis of hairless mice by sunscreens. Journal of investigative dermatology, 78(2), 181-189.

Laine, A.; Savolainen, K.; Riihimäki, V.; Matikainen, E.; Salmi, T. and Juntunen, J. (1993): Acute effects of m-xylene inhalation on body sway, reaction times, and sleep in man. International archives of occupational and environmental health, 65(3), 179-188.

Mohtashamipur, E.; Norpoth, K.; Woelke, U. and Huber, P. (1985): Effects of ethylbenzene, toluene, and xylene on the induction of micronuclei in bone marrow polychromatic 
erythrocytes of mice. Archives of toxicology, 58(2), 106-109.

Ouhtit, A.; Muller, H.K.; Davis, D.W.; Ullrich, S.E.; McConkey, D. and Ananthaswamy, H.N. (2000): Temporal events in skin injury and the early adaptive responses in ultravioletirradiated mouse skin. The American journal of pathology, 156(1), 201-207.

Protection, E. (2000): Voluntary Children's Chemical Evaluation Program (VCCEP) Tier 1 Pilot Submission. Docket Number OPPTS, 00274D.

Richer, C.-L.; Chakrabarti, S.; Senecal-Quevillon, M.; Duhr, M.; Zhang, X. and Tardif, R. (1993): Cytogenetic effects of low-level exposure to toluene, xylene, and their mixture on human blood lymphocytes. International archives of occupational and environmental health, 64(8), 581-585.

Saeed, A.K. and Salmo, N. (2012): Epidermal growth factor receptor expression in mice skin upon ultraviolet B exposure-Seborrheic Keratosis as a coincidental and unique finding. Advanced biomedical research, 1, 59.

Savolainen, H.; Vainio, H.; Helojoki, M. and Elovaara, E. (1978): Biochemical and toxicological effects of short-term, intermittent xylene inhalation exposure and combined ethanol intake. Archives of toxicology, 41(3), 195-205.

Savolainen, K.; Kekoni, J.; Riihimäki, V. and Laine, A. (1984): Immediate effects of m-xylene on the human central nervous system. In Disease,
Metabolism and Reproduction in the Toxic Response to Drugs and Other Chemicals. Springer Berlin Heidelberg, 412-417.

Savolainen, K.; Riihimäki, V.; Laine, A. and Kekoni, J. (1981): Short-term exposure of human subjects to m-xylene and 1, 1, 1trichloroethane. International archives of occupational and environmental health, 49(1), 89-98.

Savolainen, K.; Riihimäki, $V$. and Linnoila, $M$. (1979): Effects of short-term xylene exposure on psychophysiological functions in man. International archives of occupational and environmental health, 44(4), 201-211.

Tardif, R.; Laparé, S.; Plaa, G. and Brodeur, J. (1991): Effect of simultaneous exposure to toluene and xylene on their respective biological exposure indices in humans. International archives of occupational and environmental health, 63(4), 279-284.

Tsukahara, K.; Moriwaki, S.; Hotta, M.; Fujimura, T.; Sugiyama-Nakagiri, Y.; Sugawara, S.; Kitahara, T. and Takema, Y. (2005): The effect of sunscreen on skin elastase activity induced by ultraviolet-A irradiation. Biological and Pharmaceutical Bulletin, 28(12), 2302-2307.

Ullrich, S.E.; Kripk, M.L. and Ananthaswamy, H.N. (2002): Mechanisms underlying UV-induced immune suppression: implications for sunscreen design. Experimental dermatology, 11(s1), 13-1

\section{الاصابات المرضية في اعضاء الجسم المتعددة بعد التعرض المزمن للزايلين والحزمة فوق البنفسجية في الفئران

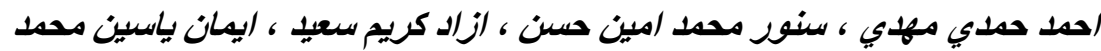

Email: azad.saeed@univsul.edu.iq

Assiut University web-site: www.aun.edu.eg

يتعرض الناس خلال فترة الحياة الى عدة ضغوطات بيئية وكيميائية والتي تنتج تاثير ات ضارة. هذه الدر اسة صمدت لبحث التاثير ات

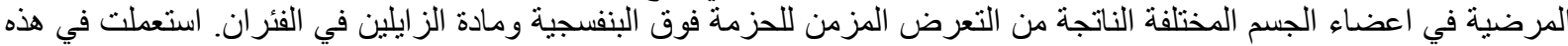

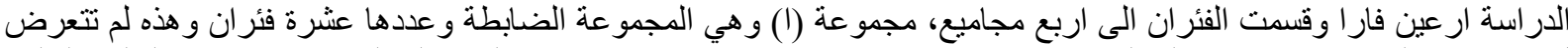

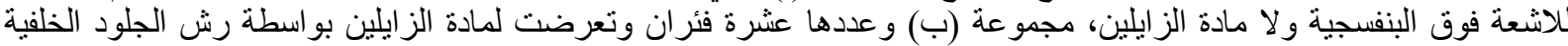

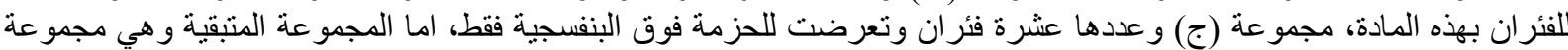

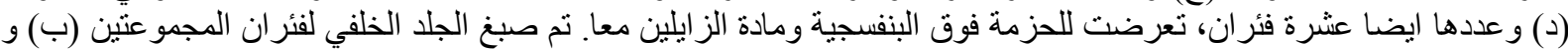

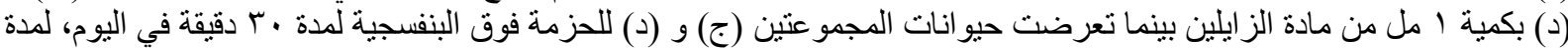

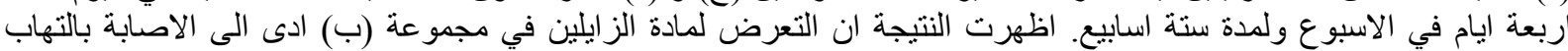

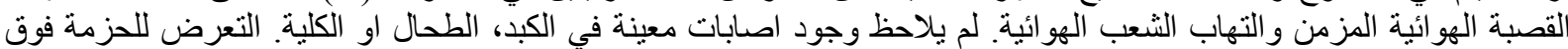

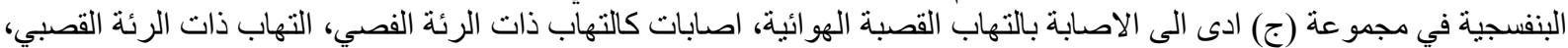

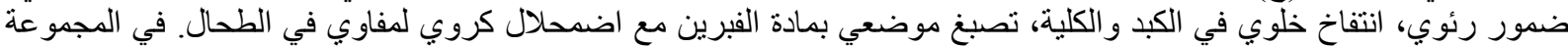

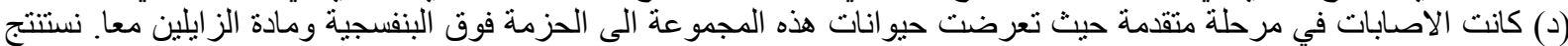

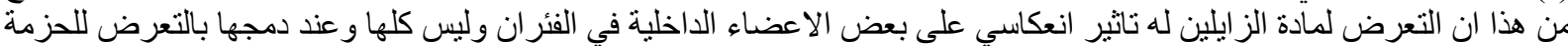

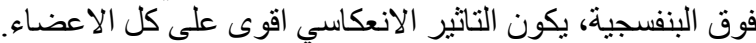

